\title{
Ethylene-dependent effects of fusaric acid on the photosynthetic activity of tomato plants
}

\author{
N. IQBAL, Z. CZÉKUS, A. ÖRDÖG, and P. POÓR ${ }^{+}$ \\ Department of Plant Biology, University of Szeged, Közép fasor 52, H-6726 Szeged, Hungary
}

\begin{abstract}
Fusaric acid (FA) is one of the potential toxins produced by pathogenic Fusarium species which exerts oxidative stress and cell death in plants. In this work, the effects of different concentrations of FA were investigated on the photosynthetic activity in leaves of wild type and Never ripe $(\mathrm{Nr})$ tomato plants to reveal the potential role of ethylene under mycotoxin exposure. FA induced a significant ethylene emission from leaves in a concentration- and timedependent manner. FA $(1 \mathrm{mM})$ decreased the maximal and effective quantum yields of PSII and PSI in both tomato genotypes but photoprotective processes, such as the nonphotochemical quenching and the cyclic electron flow, were activated more effectively in $N r$ plants. However, the lipid peroxidation was higher in leaves of $N r$. Our result confirmed that $N r$ plants were more sensitive to FA phytotoxicity suggesting the key role of ethylene in the activation of defense responses.
\end{abstract}

Keywords: assimilation; electrolyte leakage; lipid peroxidation; mycotoxin; photosystem; stomatal conductance.

\section{Introduction}

The ascomycete Fusarium oxysporum (F. oxysporum) is one of the most significant fungal plant pathogens, which results in Fusarium wilt and causes serious economic losses in various plant species worldwide, especially in tomato plants (Marzano et al. 2013). The symptoms of
F. oxysporum infection are well-characterized in tomato, such as loss of turgidity and changes in photosynthetic pigment contents of leaves that eventually cause death (Singh et al. 2017). Moreover, xylem vessels are blocked with the mycelium biomass, polysaccharide production, and spore formation by Fusarium species; these are considered as the leading causes of water imbalance and

\section{Highlights}

- Fusaric acid (FA) induced significant ethylene emission in tomato plants

- FA decreased $F_{v} / F_{m}$ and effective quantum yields of PSII and PSI

- NPQ and CEF were activated more effectively upon FA in the lack of ethylene
Received 20 January 2021

Accepted 23 April 2021

Published online 11 June 2021

${ }^{+}$Corresponding author

phone/fax: +36-62-544-307

e-mail: poorpeti@bio.u-szeged.hu

Abbreviations: ACC - 1-aminocyclopropane-1-carboxylic acid; Car - carotenoids; CEF - cyclic electron flow; Chl - chlorophyll; EL - electrolyte leakage; ET - ethylene; ETR1 - ethylene receptor 1; $\mathrm{F}_{0}$ - minimal fluorescence yield in the dark-adapted state; FA - fusaric acid; FB1 - Fumonisin B1; FM - fresh mass; $F_{\mathrm{v}} / F_{\mathrm{m}}$ - maximum quantum yield of PSII; HR - hypersensitive response; MDA - malondialdehyde; NPQ - nonphotochemical quenching; $N r$ - Never ripe; PCD - programmed cell death; $\mathrm{q}_{\mathrm{L}}$ - estimates the fraction of open PSII centres; $\mathrm{q}_{\mathrm{p}}$ - photochemical quenching; RC - reaction centres; ROS - reactive oxygen species; SA - salicylic acid; WT - wild type, $\mathrm{Y}_{(\mathrm{I})}$ - effective quantum yield of PSI; $\mathrm{Y}_{(\mathrm{II})}$ - effective quantum yield of PSII; $\mathrm{Y}_{(\mathrm{CEF})}$ - yield of cyclic electron flow around PSI; $\mathrm{Y}_{(\mathrm{NA})}$ - quantum yield of nonphotochemical energy dissipation in PSI due to acceptor side limitation; $\mathrm{Y}_{(\mathrm{ND})}-$ quantum yield of nonphotochemical energy dissipation in PSI due to donor side limitation.

Acknowledgements: This work was supported by the grant from the National Research, Development and Innovation Office of Hungary - NKFIH (grant no. NKFIH FK 124871) and by the UNKP-20-3-SZTE-512 and the UNKP-20-5 New National Excellence Program of the Ministry of Human Capacities and by and the University of Szeged Open Access Fund (5156). Péter Poór was supported by the János Bolyai Research Scholarship of the Hungarian Academy of Sciences.

Conflict of interest: The authors declare that they have no conflict of interest. 
Fusarium wilt in the host plants (Dong et al. 2012, Srinivas et al. 2019). Due to clogged xylem vessels, the disturbance of water homeostasis and nutrition uptake can affect the synthesis of photosynthetic pigments resulting in decreased photosynthetic activity (Srinivas et al. 2019). At the same time, the pathogenicity of Fusarium species is mediated by various mycotoxins produced by the fungi, such as lycomarasmin, dehydrofusaric acid, fumonisin B1 (FB1), and fusaric acid (FA), one of the most prevalent mycotoxins (Lievens et al. 2008, Rani et al. 2009, Singh et al. 2017). These toxins can disturb and inhibit the normal plant life in several ways but results of the accurate investigations of these toxins in the host plants are confined and needed to be explored in more details, especially in the case of FA. FA plays a crucial role in disease progression in plants because of its involvement in the Fusarium wilt with several symptoms (Kuźniak 2001, Singh et al. 2017). Furthermore, FA is a host nonspecific mycotoxin and its huge production is linked with the severity of disease in plants depending upon the pathogenic Fusarium species. FA is accumulated in cereal grains during infection and causes potential toxicity in animals and humans through food (Singh and Upadhyay 2014, Singh et al. 2017). However, most of the subcellular changes induced by FA are left unexplored and require much more attention for a comprehensive understanding of hidden mechanisms under stress conditions.

FA is responsible for significant changes in tomato plants, such as necrosis in leaves, shrinkage, and dryness of leaves, and wilting of petioles and stem. Similarly, the root and root hair growth is also reduced due to FA and results in the induction of transitory membrane hyperpolarization (Bouizgarne et al. 2006). FA also perturbs various biochemical processes associated with membrane permeability, hindrance of respiration, and disruption of mitochondrial activity in tomato (Singh et al. 2017). It is also known that FA increases the electrolytic leakage perturbing the depolarization potential of the plasma membrane that reduces the ATP synthesis and hinders other enzymatic activities responsible for the respiratory disorder and finally, induces cell death in tomato (Singh and Upadhyay 2014). Concurrently, low FA concentrations might evoke several protective responses in plants instead of potential phytotoxic effects and play a signaling role in host-pathogen interactions (Bouizgarne et al. 2006). Nevertheless, a scientific study revealed the phytotoxic effects of FA in banana seedlings infected with $F$. oxysporum. The results showed the reduced rates of both transpiration and stomatal conductance as well as damaged membrane system were due to FA (Dong et al. 2012). The homeostasis of cells and the status of cell membranes upon toxins are highly dependent on the production and metabolism of reactive oxygen species (ROS) (Gill and Tuteja 2010). ROS can be generated by apoplastic peroxidases, the plasma-membrane-bound NADPH-oxidase or by mitochondria and chloroplasts (Chen et al. 2010). The concentration-dependent ROS accumulation can lead to changes in the expression of defense-related genes and/or trigger programmed cell death (PCD) in plants (Sunil et al. 2013, Ivanov et al.
2018, Khan et al. 2018, Farooq et al. 2019). In parallel, a defensive mechanism is activated in plants to regulate ROS metabolism (Czarnocka and Karpiński 2018, Noctor et al. 2018, Wu et al. 2020). Plants have various antioxidants (e.g., ascorbate, glutathione, tocopherol) and antioxidant enzymes (e.g., superoxide dismutase, catalase, ascorbate peroxidases, glutaredoxins, and peroxiredoxins) to limit excess ROS contents (Xia et al. 2015). In the case of FA, a decrease in the catalase and ascorbate peroxidase activities and the high ROS production were measured in tobacco cell suspensions after a treatment with the fungal toxin. FA also reduced the ATP content and mitochondrial membrane potential, thus the significant changes in mitochondria can contribute to excess ROS (Jiao et al. 2014). In addition, FA evoked oxidative stress $\left(\mathrm{H}_{2} \mathrm{O}_{2}\right.$ and $\mathrm{O}_{2}{ }^{-}$) and perturbed antioxidant enzymatic activities (catalase and ascorbate peroxidase) in leaves and tomato cell cultures (Singh and Upadhyay 2014). At the same time, the effects of FA-induced ROS, especially, the role of chloroplasts and the changes in the photosynthetic activity upon FA have not been investigated yet.

It is known that some significant mycotoxins play a detrimental role in chloroplast structure and function as well as an induction of ROS accumulation in chloroplasts. The surplus ROS results in the degradation of D1 protein, lipid peroxidation of the thylakoid membrane, and photoinhibition of PSI and PSII (Choudhury and Behera 2001, Edelman and Mattoo 2008, Partelli et al. 2011, Chen et al. 2012, Pospíšil 2012, Xiang et al. 2013, FagundesNacarath et al. 2018, Eagles et al. 2019, Wang et al. 2020). For instance, Eupatorium adenophorum was treated with tenuazonic acid, which caused necrosis on the leaves and induced direct ROS burst in chloroplasts. This mycotoxin damaged chloroplasts and inhibited the PSII electron transport beyond $\mathrm{Q}_{\mathrm{A}}$ as well as caused the reduction of end acceptors on the PSI acceptor side and chloroplast ATPase activity. The excessive chloroplastic ROS production affected the lipids, pigments, proteins, and DNA followed by lipid peroxidation, disruption of the cell membrane, electrolytic leakage, chlorophyll (Chl) breakdown, nuclear damage, and eventually, led to the cell death of plants (Chen et al. 2010, 2014). Another significant mycotoxin, FB1, can also induce the cell death due to ROS production (Asai et al. 2000, Radić et al. 2019). It was found that ROS accumulation resulted in the dysfunction of chloroplasts and provoked the cell death in leaves of Arabidopsis (Xing et al. 2013). Similarly, FB1 triggered hypersensitive response (HR) by ROS in Arabidopsis and increased contents of long-chain bases and long-chain bases phosphates. The phosphorylated compounds of long-chain bases are synthesized by sphingosine kinases (SPHKs) which play an important role in modulating ROS production. It was demonstrated that the overexpression of Arabidopsis SPHK1 enhanced ROS accumulation while SPHK1 suppression resulted in reduced ROS contents (Qin et al. 2017). Likewise, the effect of lycomarasmin and FA produced by $F$. oxysporum resulted in the cell death of tomato leaf protoplasts (Sutherland and Pegg 1992, Stępień et al. 2013). Similarly, the phytotoxic effect of 9,10-dehydrofusaric acid isolated 
from $F$. nygamai was detected in pea leaves. In addition, 9,10-dehydrofusaric acid caused tomato leaf chlorosis and hindered root elongation (Brown et al. 2012, Bani et al. 2014). Thus, the mycotoxin-induced ROS production, Chl breakdown, membrane injury, and the cell death can be results of significant changes in chloroplast structure and photosynthetic activity which can contribute to the pathogenicity but the exact role of various mycotoxins in these processes remaines mostly unclear, especially in the case of FA.

The defense mechanisms of plants are regulated by various phytohormones, such as ethylene (ET) which biosynthesis and effects can be dependent on ROS (Chang 2016). It is known that ROS evoke several ETtriggered responses in various plant species. In addition, molecular studies have revealed that ET and NADPH oxidase function together to control ROS production under various abiotic stress effects (Jiang et al. 2013). ET caused stomatal closure in Arabidopsis through $\mathrm{H}_{2} \mathrm{O}_{2}$ production by respiratory burst oxidase homolog protein F (RbohF) (Jiao et al. 2013). Moreover, the ethylene receptor 1 (ETR1) and the ethylene insensitive 2 (EIN2)-induced signaling was essential for ROS accumulation (He et al. 2011) which contributes to stomatal closure and immunizes plants against pathogens attacks (Mersmann et al. 2010). ET regulated the ROS production and hindered the constitutive triple response (CTR1) by activating the mitogen-activated protein kinase 3/6 (MAPK 3/6) signaling cascade (Xia et al. 2015). Furthermore, ethylene response factor 6 (ERF6) was also phosphorylated by MPK6 and ERF6 inducing the transcriptional control of ROS-responsive genes. Moreover, both ET and ROS together in a self-amplifying forward loop can induce cell death in plants in response to various environmental stimuli (Wang et al. 2013a). It was shown that many mycotoxins induced cell death by rapidly generating gaseous ET. The key effect of ET in DNA fragmentation and PCD induction was reported after the treatment with mycotoxin zearalenone and its derivatives in maize (Repka et al. 2017). Moreover, it was found that FB1-induced PCD is also dependent on the ET based on the application of ET receptor mutant etr1-1 Arabidopsis plants (Asai et al. 2000). Later, it was demonstrated that degradation of $\mathrm{Chl}$ and promotion of cell death were more rapid and more extensive in the ET receptor mutant etr 1-1, but these tendencies were different in other ET receptor mutants (Plett et al. 2009). Despite, the role of ET on the regulation of photosynthetic pigment contents and photosynthetic activity has been investigated (Chen and Gallie 2015, Borbély et al. 2019), currently acquired knowledge about ET in signaling of mycotoxin-induced physiological changes, especially in photosynthesis, remained mostly incomplete and needs further research. Using ET sensingor signaling mutants can provide new results to understand the role of ET in FA-induced changes in photosynthetic activity, respectively. There are seven ET receptors (SIETR1-7) in tomato but only five of them can bind ET with high affinity (Kamiyoshihara et al. 2012, Shakeel et al. 2013, Liu et al. 2015). Among these, SIETR3 is known as Never ripe $(\mathrm{Nr})$ which is the ortholog of the
Arabidopsis ETR1 (Yen et al. 1995, Klee and Tieman 2002). $N r$ plants exhibit insensitivity to ET in all tissues but are able to produce ET, e.g., upon pathogen attack, indicating that mutants are not impaired in ET biosynthesis (Lanahan et al. 1994). Using this mutant provides a more precise analysis of the physiological and biochemical functions of ET (Nascimento et al. 2020).

In this article, an analysis of the ET-dependent photosynthesis was carried out in leaves of wild-type and ET receptor mutant Never ripe $(\mathrm{Nr})$ tomato plants exposed to a sublethal $(0.1 \mathrm{mM})$ and a cell-death-inducing concentration $(1 \mathrm{mM})$ of FA to reveal the differences in the main photosynthetic parameters after the mycotoxin treatments. In addition, FA-induced physiological changes were also elucidated in the two tomato genotypes.

\section{Materials and methods}

Plant material: Wild type (WT) and ET-receptor mutant Never ripe $(\mathrm{Nr})$ seeds of tomato (Solanum lycopersicum L., cv. Ailsa Craig) were germinated in dark and then plants were grown hydroponically in a greenhouse with 12-h light and 12-h dark period at day/night temperatures of $24 / 22^{\circ} \mathrm{C}$ and irradiance of $200 \mu \mathrm{mol}$ (photon) $\mathrm{m}^{-2} \mathrm{~s}^{-1}$ [PPFD; white LED $(5700 \mathrm{~K})$ illumination supplemented with FAR LEDs; PSI, Drásov, Czech Republic] and relative humidity of $55-60 \%$ for four weeks. The nutrient solution was changed three times a week (Poór et al. 2011). The experiments were conducted with 6- to 7-week-old intact plants at the stage of 7-8 developed leaves.

Fusaric acid treatment: Tomato plants were treated in the greenhouse with $100 \mu \mathrm{M}$ and $1 \mathrm{mM}$ FA concentrations prepared in nutrient solution (Wang et al. 2013b) avoiding any artificial injury or wound. Control plants were provided with the nutrient solution only without the addition of FA. The fully expanded leaves on the $3^{\text {rd }}$ or $4^{\text {th }}$ stem from the top were selected for all measurements. The effects of FA on tomato leaves were recorded after 24 and $72 \mathrm{~h}$ following the treatment.

Ethylene production: The total ethylene gas produced by tomato leaves was measured after FA treatments with a Hewlett Packard 5890 Series II gas chromatograph equipped with a flame ionization detector and a column packed with activated alumina as described by Poór et al. (2015). Leaf samples $(0.5 \mathrm{~g})$ were incubated with $0.5 \mathrm{~mL}$ of deionized water for $1 \mathrm{~h}$ in gas-tight tubes under darkness. After the incubation, $2.5 \mathrm{~mL}$ of the gas was removed from the flasks with a gas-tight syringe and injected to gas chromatograph. A set of ethylene standards was used to calculate the amount of ethylene generated by the leaves.

Photosynthetic activity: Chl $a$ fluorescence and P700 redox state were analysed with Dual-PAM-100 instrument (Heinz-Walz, Effeltrich, Germany) (Klughammer and Schreiber 1994, 2008). Leaves were dark-adapted for $15 \mathrm{~min}$ at room temperature before the measurement of the minimal fluorescence yield of the dark-adapted state $\left(\mathrm{F}_{0},\right)$ applying weak measuring light when reaction centres 
(RC) are open. The maximal fluorescence in the darkadapted state $\left(\mathrm{F}_{\mathrm{m}}\right)$ was determined using a pulse $(800 \mathrm{~ms})$ of saturating light $\left[12,000 \mu \mathrm{mol}\right.$ (photon) $\left.\mathrm{m}^{-2} \mathrm{~s}^{-1}\right]$. After illumination with actinic light $\left[220 \mu \mathrm{mol}\left(\right.\right.$ photon) $\left.\mathrm{m}^{-2} \mathrm{~s}^{-1}\right]$, the light-adapted steady-state fluorescence $\left(\mathrm{F}_{\mathrm{s}}\right)$ was determined and the maximum fluorescence level $\left(\mathrm{F}_{\mathrm{m}}{ }^{\prime}\right)$ in the light-adapted state was recorded with saturating pulses. Thereafter, the actinic light was turned off and the minimum fluorescence level in the light-adapted state $\left(\mathrm{F}_{0}{ }^{\prime}\right)$ was measured by illuminating the leaf with 3 -s far-red light $\left[5 \mu \mathrm{mol}\right.$ (photon) $\left.\mathrm{m}^{-2} \mathrm{~s}^{-1}\right]$. The following parameters were determined: the maximum quantum yield of PSII [variable fluorescence $\left(\mathrm{F}_{\mathrm{v}}\right)$ /maximum fluorescence $\left(\mathrm{F}_{\mathrm{m}}\right)$ ], the minimal fluorescence yield in the dark-adapted state $\left(\mathrm{F}_{0}\right)$, the maximal fluorescence yield in the dark-adapted state $\left(\mathrm{F}_{\mathrm{m}}\right)$, the fraction of open PSII RC $\left(\mathrm{q}_{\mathrm{L}}\right)$, the quantum yields of PSI $\left(\mathrm{Y}_{(\mathrm{I})}\right)$ and PSII [ $\left.\mathrm{Y}_{(\mathrm{II})}\right]$, the nonphotochemical quenching (NPQ), the quantum yield of nonphotochemical energy dissipation due to acceptor side limitation [Y $\left.\mathrm{Y}_{(\mathrm{NA})}\right]$, the quantum yield of nonphotochemical energy dissipation due to donor side limitation $\left[\mathrm{Y}_{(\mathrm{ND})}\right]$, and the photochemical quenching coefficient ( $\mathrm{q}_{\mathrm{p}}$ ) (Zhang et al. 2014, Poór et al. 2019). The ratio of the quantum yield of cyclic electron flow (CEF) to the linear electron flow was calculated as $\mathrm{Y}_{(\mathrm{CEF})} / \mathrm{Y}_{(\mathrm{II})}=\left[\mathrm{Y}_{(\mathrm{I})}-\mathrm{Y}_{(\mathrm{II})}\right] / \mathrm{Y}_{\text {(II) }}$ (Lei et al. 2014).

Moreover, the stomatal conductance $\left(g_{\mathrm{s}}\right)$ and the net photosynthetic rate $\left(P_{\mathrm{N}}\right)$ were measured on the fully expanded leaves using a portable photosynthesis system (LI-6400, LI-COR, Inc., Lincoln, NE), as described by Poór et al. (2011). Leaves were illuminated (PPFD of 200 $\left.\mu \mathrm{mol} \mathrm{m} \mathrm{m}^{-2} \mathrm{~s}^{-1}\right)$ in the chamber and data were recorded after $10 \mathrm{~min}$. Conditions were constant during the measurements $\left(25^{\circ} \mathrm{C}, 65 \pm 10 \%\right.$ relative humidity, and controlled $\mathrm{CO}_{2}$ supply of $400 \mu \mathrm{mol} \mathrm{mol}{ }^{-1}$ ).

Photosynthetic pigment: $\mathrm{Chl}(a+b)$ and carotenoid (Car) contents were determined in accordance with the protocol by Sims and Gamon (2002) with some modifications. Approximately $25 \mathrm{mg}$ of leaves were crushed in $100 \%$ acetone and left for $24 \mathrm{~h}$ in the dark at $4^{\circ} \mathrm{C}$. Samples were centrifuged $\left(12,000 \times \mathrm{g}, 15 \mathrm{~min}, 4^{\circ} \mathrm{C}\right)$ and the pellet was extracted again with $1 \mathrm{ml}$ of cold acetone/Tris buffer solution $(80: 20, \mathrm{v} / \mathrm{v}, \mathrm{pH}=7.8)$ for $24 \mathrm{~h}$ in the dark at $4^{\circ} \mathrm{C}$. After centrifugation $\left(12,000 \times \mathrm{g}, 15 \mathrm{~min}, 4^{\circ} \mathrm{C}\right)$, the supernatants were collected, and the pigment content was measured by a spectrophotometer (Kontron, Milano, Italy) at $470,537,647$, and $663 \mathrm{~nm}$, respectively.

Lipid peroxidation: Lipid peroxidation was determined based on the malondialdehyde (MDA) content according to Ederli et al. (1997). Leaf samples (100 mg) were ground in liquid nitrogen and then, $1 \mathrm{ml}$ of $0.1 \%$ trichloroacetic acid (TCA) and $0.4 \%$ butyl hydroxytoluene (BHT) were added to avoid further lipid peroxidation. After centrifugation $\left(12,000 \times g, 20 \mathrm{~min}, 4^{\circ} \mathrm{C}\right), 500 \mu \mathrm{l}$ of supernatant was added to $2 \mathrm{ml}$ of $20 \%$ TCA containing $0.5 \%$ thiobarbituric acid (TBA) and heated at $100^{\circ} \mathrm{C}$ for $30 \mathrm{~min}$. Samples were cooled down in the next step and their absorbance was determined at 532 and $600 \mathrm{~nm}$ by a spectrophotometer (Kontron, Milano, Italy). Total MDA content was quantified by using $155 \mathrm{mM}^{-1} \mathrm{~cm}^{-1}$ molar extinction coefficient and expressed in nmol $\mathrm{g}(\mathrm{FM})^{-1}$. All chemicals were purchased from Sigma-Aldrich (St. Louis, MO, USA).

Cell viability: Cell viability was determined based on the measurement of the electrolytic leakage according to Czékus et al. (2020). Leaf samples (100 mg) were added to $20 \mathrm{ml}$ of ultrapure distilled water and kept under dark conditions at $25^{\circ} \mathrm{C}$ for $2 \mathrm{~h}$. After that, the conductivity of water $\left(C_{1}\right)$ was determined, then the samples were heated at $100^{\circ} \mathrm{C}$ for $30 \mathrm{~min}$ to completely release the ions from the tissues. Subsequently, samples were cooled to room temperature and the conductivity of the water $\left(\mathrm{C}_{2}\right)$ was measured again. The electrolytic leakage (EL) percentage of all the samples was calculated using the following formula: $\mathrm{EL}[\%]=\left(\mathrm{C}_{1} / \mathrm{C}_{2}\right) \times 100$.

Statistical analysis: Each experiment contains at least three biological replicates (at least three plants per treatment) and the entire experiment was conducted three times. Results are expressed as mean \pm SE. Statistical analysis was accomplished using Sigma Plot 11.0 software (SPSS Science Software, Erkrath, Germany). Differences between the treatments in the case of each plant species were statistically analyzed by analysis of variance (ANOVA) using Tukey's test. The means of each treatment were significant if $p \leq 0.05$.

\section{Results}

Ethylene production: Even though phytohormones play a crucial role in defense reactions influenced by photosynthesis, the role of ET in mycotoxin-induced defense responses has remained less-studied. To gain more information about the ET-dependent changes in photosynthesis triggered by FA, the production of ET was measured in the leaves of WT and $N r$ tomato plants after treatments by two concentrations of mycotoxin.

The ET emission was significantly enhanced in the concentration- and time-dependent manner in WT plants, where treatment with $1 \mathrm{mM}$ FA resulted in the highest production of ET (Fig. 1). Similar changes were observed in $N r$ plants treated by FA, but ET production did not show any significant temporal differences in the examined genotypes following the treatments after 24 and $72 \mathrm{~h}$, respectively (Fig. 1).

Photosynthetic activity: The maximal quantum yield $\left(\mathrm{F}_{\mathrm{v}} / \mathrm{F}_{\mathrm{m}}\right)$ of PSII did not show any significant differences after the treatments with $0.1 \mathrm{mMFA}$ during the investigated time period in neither of the genotypes. At the same time, $1 \mathrm{mM}$ FA significantly decreased $\mathrm{F}_{\mathrm{v}} / \mathrm{F}_{\mathrm{m}}$ after $72 \mathrm{~h}$ in both tomato genotypes (Fig. 2A). The minimal fluorescence yield of the dark-adapted state $\left(\mathrm{F}_{0}\right)$ did not change after $24 \mathrm{~h}$ in any FA treatments independently from the active ET signaling but it decreased significantly upon $1 \mathrm{mM}$ FA after $72 \mathrm{~h}$ in WT as compared to the control (Fig. 2B). The maximal fluorescence in dark-adapted state $\left(\mathrm{F}_{\mathrm{m}}\right)$ was reduced gradually in accordance with the increasing 
FA concentration after $72 \mathrm{~h}$ in WT but changes were not pronounced in $\mathrm{Nr}$ leaves as compared to WT (Fig. 2C). The $\mathrm{q}_{\mathrm{L}}$ parameter, which is in good correlation with the number of the open PSII RC, did not change during the first $24 \mathrm{~h}$ but it significantly declined after $72 \mathrm{~h}$ under $1 \mathrm{mM}$ FA treatment in both genotypes. At the same time, no significant differences can be found in all FA treatments as well as between WT and $N r$ (Fig. 2D).

The effective quantum yield of PSII [ $\left.\mathrm{Y}_{(\mathrm{II})}\right]$ significantly decreased upon increasing FA concentration in all treatments. The highest $\mathrm{Y}_{\text {(II) }}$ reduction was observed in $1 \mathrm{mM}$ FA-treated plants after 24 and $72 \mathrm{~h}$, respectively. Furthermore, $\mathrm{Y}_{\text {(II) }}$ did not show any significant changes between WT and $N r$ plants after 24 and 72 h (Fig. $3 A$ ). Similarly, $\mathrm{Y}_{(\mathrm{I})}$ showed the same trend as $\mathrm{Y}_{(\mathrm{II})}$ after 24 and

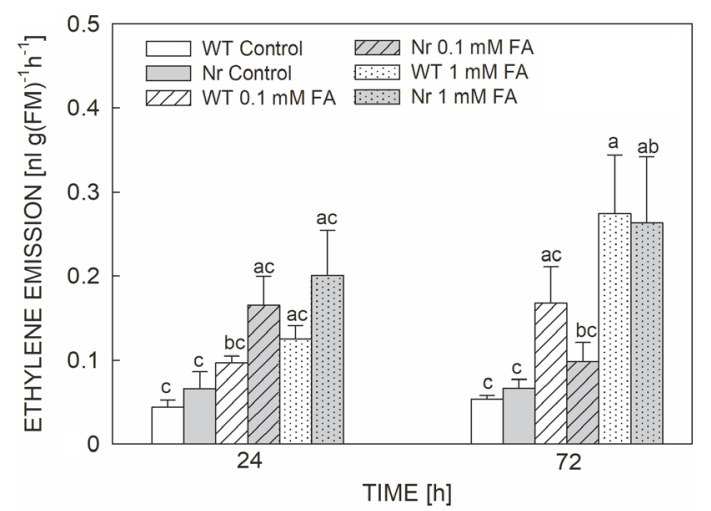

Fig. 1. Changes in the ethylene (ET) production in fully expanded leaves of wild type (WT; white columns) and ethylene-insensitive Never ripe (Nr; grey columns) tomato plants treated with $0.1 \mathrm{mM}$ or $1 \mathrm{mM}$ fusaric acid (FA) for 24 and $72 \mathrm{~h}$. Means \pm SE, $n=3$. Bars denoted by different letters are significantly different at $P \leq 0.05$ as determined by Tukey's test.
$72 \mathrm{~h}$ in $0.1 \mathrm{mM}$ and $1 \mathrm{mM}$ FA-treated plants, respectively (Fig. 3B). However, the photochemical quenching coefficient $\left(\mathrm{q}_{\mathrm{P}}\right)$ decreased significantly by both FA treatments only after $72 \mathrm{~h}$ in both genotypes (Fig. $3 \mathrm{C}$ ). On the contrary, nonphotochemical quenching (NPQ) significantly increased in the concentration-dependent manner by FA within $24 \mathrm{~h}$ which was significantly higher in $\mathrm{Nr}$ leaves. These changes were more pronounced after $72 \mathrm{~h}$ in $\mathrm{Nr}$ plants (Fig. 3E). The quantum yield of nonphotochemical energy dissipation in PSI due to donor side limitation $\left[\mathrm{Y}_{(\mathrm{ND})}\right]$ was significantly enhanced in $1 \mathrm{mM}$ FA-treated plants after 24 and $72 \mathrm{~h}$ following $0.1 \mathrm{mM}$ concentration as compared to control plants. Nevertheless, no significant changes can be observed between WT and $N r$ plants (Fig. 3D). Moreover, a gradual but not significant decline was depicted in the quantum yield of nonphotochemical energy dissipation in PSI due to acceptor side limitation $\left[\mathrm{Y}_{(\mathrm{NA})}\right]$ after $24 \mathrm{~h}$ in all FA-treated plants while changes in $\mathrm{Y}_{(\mathrm{NA})}$ were not significant after $72 \mathrm{~h}$ under FA exposure (Fig. $3 F$ ).

The ratio of the quantum yield of cyclic electron flow $(\mathrm{CEF})$ to the linear electron flow $\left[\mathrm{Y}_{(\mathrm{CEF})} / \mathrm{Y}_{(\mathrm{II})}\right]$ increased significantly only after the 72-h-long $1 \mathrm{mM}$ FA exposure in $N r$ (Fig. 4).

Photosynthetic pigments: Treatment with $1 \mathrm{mM}$ FA induced loss of Chl $(a+b)$ and Car content after $72 \mathrm{~h}$ in leaves of both genotypes as compared to controls (Fig. 5). However, this decrease in $\mathrm{Chl}(a+b)$ was more pronounced in $N r$ as compared to WT leaves (Fig. $5 A$ ).

Stomatal conductance and net photosynthetic rate: The stomatal conductance was significantly reduced after $24 \mathrm{~h}$ under $0.1 \mathrm{mM}$ and $1 \mathrm{mM}$ FA exposure in both plant genotypes and stomata remained closed after $72 \mathrm{~h}$ upon all FA treatments, respectively (Fig. 6A). Similarly, the net photosynthetic rate rapidly decreased in both WT

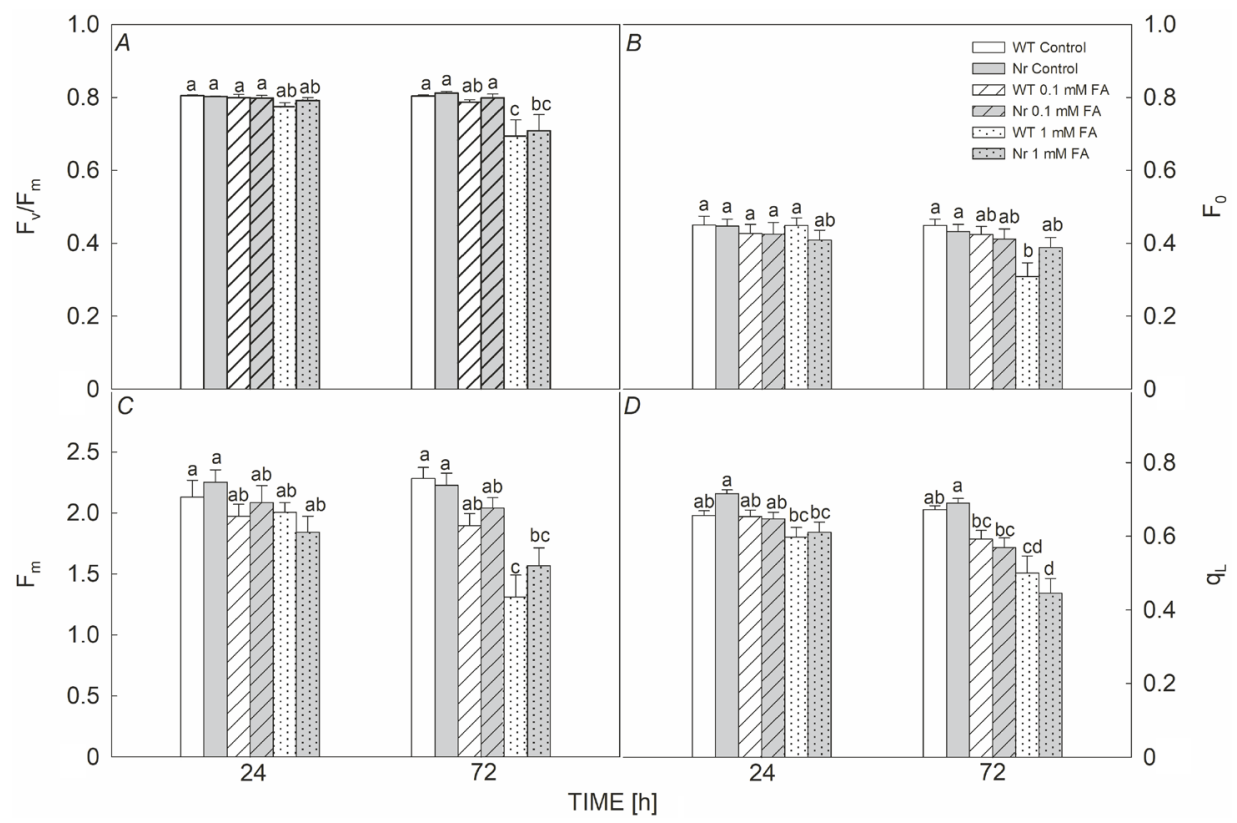

Fig. 2. Changes in the maximum quantum yield of PSII $\left(\mathrm{F}_{\mathrm{v}} / \mathrm{F}_{\mathrm{m}}\right)$ $(A)$, the minimal fluorescence yield of the dark-adapted state $\left(\mathrm{F}_{0}\right)(B)$, the maximal fluorescence in the dark-adapted state $\left(\mathrm{F}_{\mathrm{m}}\right)(\mathrm{C})$, and the fraction of open PSII reaction centres $\left(\mathrm{q}_{\mathrm{L}}\right)$ $(D)$ in fully expanded leaves of wild type (WT; white columns) and ethylene-insensitive Never ripe ( $\mathrm{Nr}$; grey columns) tomato plants treated with $0.1 \mathrm{mM}$ or $1 \mathrm{mM}$ fusaric acid (FA) for 24 and $72 \mathrm{~h}$. Means $\pm \mathrm{SE}, n=3$. Bars denoted by different letters are significantly different at $P \leq 0.05$ as determined by Tukey's test. 


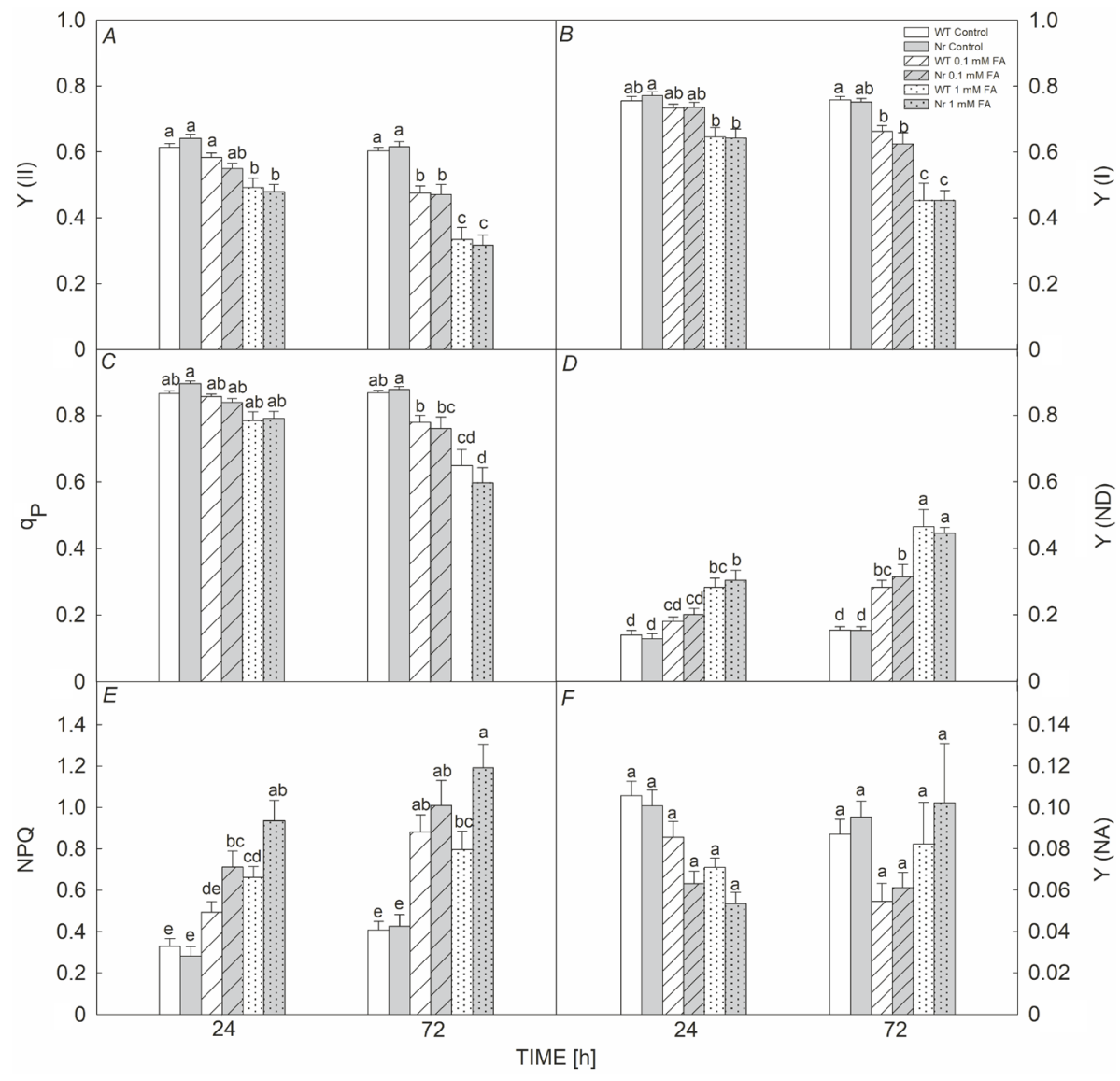

Fig. 3. Changes in the effective quantum yield of PSII [Y $\left.\mathrm{Y}_{\text {(II) }}\right](A)$, the quantum yield of PSI [Y $\left.\mathrm{Y}_{(\mathrm{I})}\right]$ $(B)$, the photochemical quenching coefficient $\left(\mathrm{q}_{\mathrm{p}}\right)(C)$, the quantum yield of nonphotochemical energy dissipation in PSI due to donor side limitation $\left[\mathrm{Y}_{(\mathrm{ND})}\right](D)$, the nonphotochemical quenching (NPQ) $(E)$, and the quantum yield of nonphotochemical energy dissipation in PSI due to acceptor side limitation $\left[\mathrm{Y}_{(\mathrm{NA})}\right](F)$ in fully expanded leaves of wild type (WT; white columns) and ethyleneinsensitive Never ripe $(\mathrm{Nr}$; grey columns) tomato plants treated with $0.1 \mathrm{mM}$ or $1 \mathrm{mM}$ fusaric acid (FA) for 24 and $72 \mathrm{~h}$. Means \pm SE, $n=3$. Bars denoted by different letters are significantly different at $P \leq 0.05$ as determined by Tukey's test.

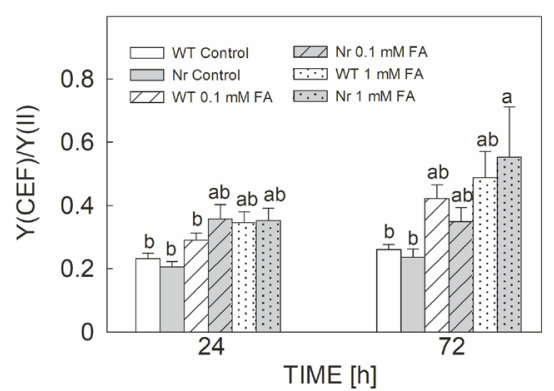

Fig. 4. Changes in the ratio of the quantum yield of cyclic electron flow $(\mathrm{CEF})$ to the linear electron flow $\left[\mathrm{Y}_{(\mathrm{CEF})} / \mathrm{Y}_{(\mathrm{II})}\right]$ in fully expanded leaves of wild type (WT; white columns) and ethylene-insensitive Never ripe ( $\mathrm{Nr}$; grey columns) tomato plants treated with $0.1 \mathrm{mM}$ or $1 \mathrm{mM}$ fusaric acid (FA) for 24 and $72 \mathrm{~h}$. Means $\pm \mathrm{SE}, n=3$. Bars denoted by different letters are significantly different at $P \leq 0.05$ as determined by Tukey's test.

and $N r$ plants upon application of $0.1 \mathrm{mM}$ and $1 \mathrm{mM} \mathrm{FA}$, respectively. Moreover, it was significantly lowered in case of the highest concentration of FA treatment as compared to $0.1 \mathrm{mM}$ (Fig. $6 B$ ).

Lipid peroxidation and cell viability: Changes in the malondialdehyde (MDA) content represent the product of the final decomposition of lipid peroxidation upon FA application in both WT and $N r$ plants. The MDA content

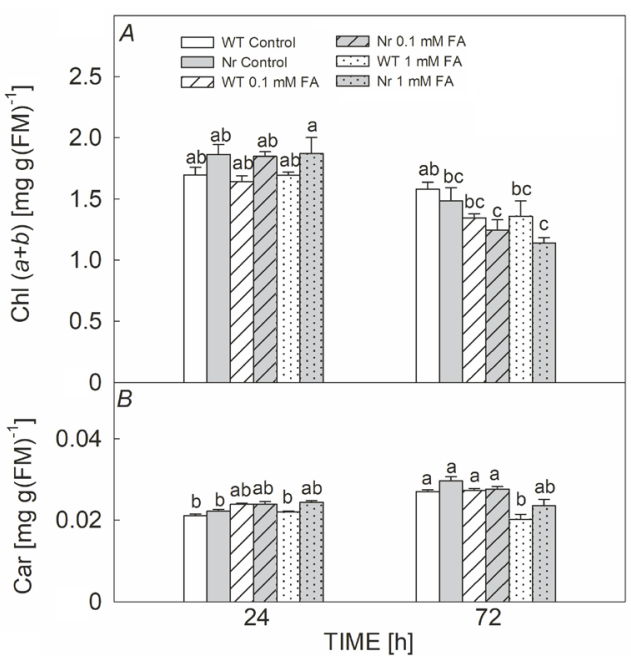

Fig. 5. Changes in chlorophyll $(a+b)[\mathrm{Chl}(a+b)](A)$ and carotenoids (Car) contents $(B)$ in fully expanded leaves of wild type (WT; white columns) and ethylene-insensitive Never ripe ( $N r$; grey columns) tomato plants treated with $0.1 \mathrm{mM}$ or $1 \mathrm{mM}$ fusaric acid (FA) for 24 and $72 \mathrm{~h}$. Means \pm SE, $n=3$. Bars denoted by different letters are significantly different at $P \leq 0.05$ as determined by Tukey's test.

was significantly higher in $1 \mathrm{mM}$ FA-treated plants after 24 and $72 \mathrm{~h}$ in $\mathrm{Nr}$ as compared to $0.1 \mathrm{mM}$ FA treatment and 
WT plants. Besides, $N r$ plants showed significantly higher MDA content already after $24 \mathrm{~h}$ under $1 \mathrm{mM}$ FA exposure as compared to WT plants (Fig. 7A). Similarly, the loss of cell viability based on the electrolyte leakage (EL) from the leaves increased under $1 \mathrm{mM}$ FA exposure after $72 \mathrm{~h}$ in both tomato genotypes. However, no significant difference was found between WT and $N r$ plants, respectively (Fig. 7B).

\section{Discussion}

Several studies have been conducted on the interplay between mycotoxin-induced ROS production and cell death (Singh et al. 2017, Farooq et al. 2019) but the origin and subcellular effects of ROS remained mostly uninvestigated. The mycotoxin FA produced by F. oxysporum f. sp. lycopersici plays a key role in the development of Fusarium wilt and results in disease symptoms, such as necrosis mediated by ROS in tomato plants (Stępień et al. 2013, Singh and Upadhyay 2014). However, it was found that the degree of cell death is highly dependent on the presence or absence of light (Asai et al. 2000, Xing et al. 2013), thus, the active photosynthesis and the injury of photosynthetic apparatus can significantly influence the outcome of mycotoxin exposure. In this research work, the FA-induced changes in photosynthetic activity were investigated to reveal the effects of FA on PSII and PSI activities. Defense reactions of plants as well as ROS production and PCD are regulated by various phytohormones under the mycotoxin exposure (Glazebrook 2005, Pare et al. 2005, Coll et al. 2011, Xing et al. 2013, Kurepin et al. 2015). Thus, we focused on

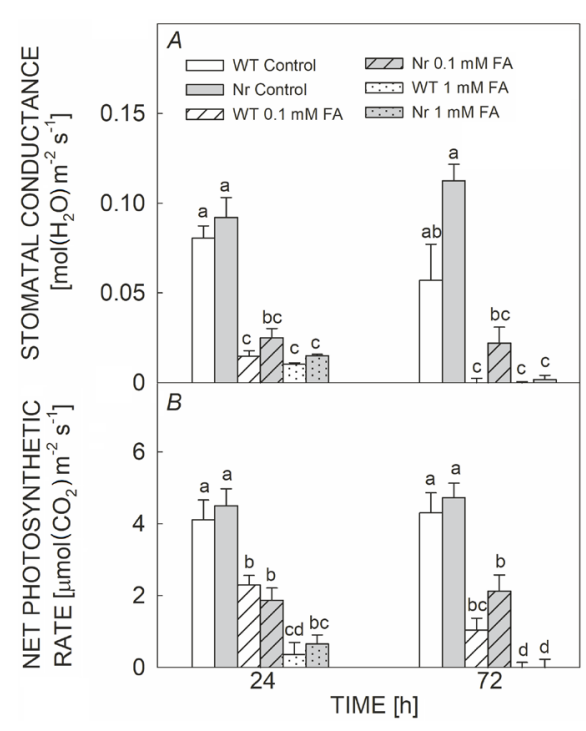

Fig. 6. Changes in the stomatal conductance $(A)$ and net photosynthetic rate $(B)$ in fully expanded leaves of wild type (WT; white columns) and ethylene-insensitive Never ripe ( $\mathrm{Nr}$; grey columns) tomato plants treated with $0.1 \mathrm{mM}$ or $1 \mathrm{mM}$ fusaric acid (FA) for 24 and $72 \mathrm{~h}$. Means \pm SE, $n=3$. Bars denoted by different letters are significantly different at $P \leq 0.05$ as determined by Tukey's test. the role of the gaseous ET in this work using ET receptor mutant $\mathrm{Nr}$ plants. Moreover, the exposure time and toxin concentration are also determining factors in the onset of disease (Singh and Upadhyay 2014, Singh et al. 2017), thus FA was applied in two different concentrations via the rooting medium (Wang et al. 2013b) and effects of the mycotoxin were recorded at different time-points (24 and $72 \mathrm{~h}$ ) after the FA exposure.

Our work revealed the enhanced level of ET emission in FA-treated leaves after 24 and $72 \mathrm{~h}$ in both tomato genotypes, respectively, depending upon the increasing FA concentration. It is known that ET by a concentrationand time-dependent manner can contribute to both PCD initiation and activation of defense responses of plants (Overmyer et al. 2003, Trobacher 2009, Poór et al. 2013). Interestingly, it was found that the degradation of $\mathrm{Chl}$ and promotion of cell death were more rapid and more extensive in the ET-receptor mutant etr 1-1 after FB1 treatment suggesting the protective role of ET in the case of this kind of Fusarium toxin (Plett et al. 2009). Moreover, others described that the exogenous treatment with ET precursor 1-aminocyclopropane-1-carboxylic acid (ACC) significantly reduced FB1-induced cell death in Arabidopsis (Wu et al. 2015). Our result based on lipid peroxidation and electrolyte leakage confirmed also that ET plays a crucial role in the activation of defense reaction of tomato plants after FA treatments. ET-dependent changes in photosynthetic activity can also serve as defense reactions of plants under mycotoxin exposure, thus the potential effects of this FA-induced ET production were further investigated on the photosynthetic activity.

Our results demonstrated that the exogenous treatment

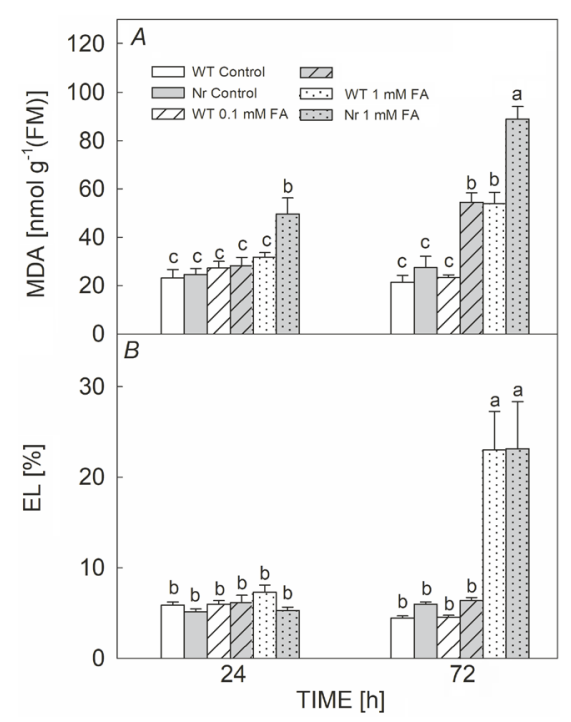

Fig. 7. Changes in the content of malondialdehyde (MDA) $(A)$ and electrolyte leakage (EL) $(B)$ in fully expanded leaves of wild type (WT; white columns) and ethylene-insensitive Never ripe (Nr; grey columns) tomato plants treated with $0.1 \mathrm{mM}$ or $1 \mathrm{mM}$ fusaric acid (FA) for 24 and $72 \mathrm{~h}$. Means \pm SE, $n=3$. Bars denoted by different letters are significantly different at $P \leq 0.05$ as determined by Tukey's test. 
with $1 \mathrm{mM}$ FA caused a significant decrease in the $F_{v} / F_{m}$ after $72 \mathrm{~h}$ independently of the presence or absence of active ET signaling. This result confirmed for the first time that FA by a concentration-dependent manner can disturb the efficiency of PSII and damage the photosynthetic apparatus. At the same time, changes in $F_{0}$ and $F_{m}$ were more significant in WT plants but the decrease in $\mathrm{q}_{\mathrm{L}}$ was more pronounced in $\mathrm{Nr}$ leaves. However, the effects of ET/ACC on photosynthesis seem to be contradictory (Ceusters and Van de Poel 2018). Borbély et al. (2019) found that neither low nor high concentration of ACC influenced the $\mathrm{F}_{\mathrm{v}} / \mathrm{F}_{\mathrm{m}}$ parameter in tomato, but it decreased $\mathrm{q}_{\mathrm{L}}$, which displays the fraction of open PSII RC. Thus, changes in this parameter upon FA can be dependent on FA-induced ET.

Time- and concentration-dependent changes in $\mathrm{Y}_{(\mathrm{II})}$, $\mathrm{q}_{\mathrm{P}}$, and NPQ were recorded after FA treatments because of photoinhibition in PSII by FA exposure. The photoinhibition of PSII by tenuazonic acid and FB1 has also been reported earlier (Guo et al. 2020, Zavafer et al. 2020). Thereafter, the excessive photoexcitation pressure is exerted at PSII RC resulting in ROS production in the form of $\mathrm{O}_{2}{ }^{-},{ }^{1} \mathrm{O}_{2}$, and $\mathrm{H}_{2} \mathrm{O}_{2}$. These oxidant species are detrimental to other electron transport components and might damage the protein structure of PSII, respectively (Liu et al. 2012, Zhang et al. 2014). Plants have evolved several photoprotective mechanisms to lessen the deleterious effects of ROS accumulation by activating defense systems, such as HR at the infection site, antioxidant production, and NPQ operation (Xing et al. 2013). NPQ mechanisms are capable to disperse excessive energy captured by LHCII (Liu et al. 2012). Moreover, the increase in NPQ is a good indicator of the onset of photoprotective mechanisms, which are mostly related to the xanthophyll cycle and the formation of $\Delta \mathrm{pH}$ across the thylakoid membranes (Miyake 2010, Zhang et al. 2014). Our findings revealed that NPQ increased by FA in the concentration-dependent manner and $\mathrm{Nr}$ showed a significant elevation of NPQ as compared to WT. Exogenous ACC treatment also decreased $\mathrm{Y}_{\text {(II) }}$ which was accompanied by increasing NPQ in tomato leaves (Borbély et al. 2019). Moreover, others also confirmed that ET significantly affected NPQ in eto 1-1 ET overproducing and ctr1-3 constitutive ET response of Arabidopsis mutants. These plants showed the inhibition in the conversion of violaxanthin to zeaxanthin, thus in the efficiency of the xanthophyll cycle due to their impaired violaxanthin deepoxidase activity. Based on this observation, the excess ET or constitutive ET signaling inhibited the activity of xanthophyll cycle in eto1-1 or ctr1-3 (Chen and Gallie 2015). Based on our results, FA-induced ET played a role mainly in the protection mechanism of photosynthesis through the development of NPQ and CEF. Not only $Y_{(I)}$ but also $\mathrm{Y}_{(\mathrm{I})}$ was downregulated by $\mathrm{FA}$. These changes occurred in parallel with higher $\mathrm{Y}_{(\mathrm{ND})}$ and lower $\mathrm{Y}_{(\mathrm{NA})}$. Besides, the reduction of PSI acceptor side and NADPH accumulation led to photoinhibition of PSI. Usually, the overproduction of NADPH results from a reduced level of carbon fixation that can eventually increase the production of hydroxyl radicals (Kalaji et al. 2012, Zhang et al. 2014). Consequently, Chl triplets are formed due to the overreduced acceptor side of PSI evolving harmful singlet oxygen. Moreover, NADPH accumulation speeds up the Mehler reaction which ultimately produces harmful superoxide radicals. Eventually, ROS accumulation causes damage to PSI by photoinhibition (Huang et al. 2011). In contrast, the gradual increase in $\mathrm{Y}_{(\mathrm{ND})}$ parameter can be caused by induction of CEF under FA stress, especially after $1 \mathrm{mM}$ FA treatment. Hence, CEF plays a crucial role against photoinhibition by protecting PSI, while conversely, CEF can direct extra electron flow towards $\mathrm{O}_{2}$ and NADPH to decrease ROS production. In addition, CEF also has the capacity to consume excessive reduced NADPH via NADPH dehydrogenase-dependent route (Shikanai 2007, 2014; Huang et al. 2011, Zhang et al. 2014). Furthermore, CEF plays an important role across the thylakoid membrane by producing a proton gradient via shifting electrons from PSI to PQ which is essential for PSII protection by dispersing excessive light energy (Munekage et al. 2002, Takahashi et al. 2009, Jahns and Holzwarth 2012). Our results showed the ascending trend of the CEF parameter in a FA concentration-dependent manner. Moreover, $\mathrm{Y}_{(\mathrm{CEF})} / \mathrm{Y}_{(\mathrm{II})}$ like NPQ was significantly higher in $N r$ as compared to WT following $1 \mathrm{mM} \mathrm{FA}$ after $72 \mathrm{~h}$. Therefore, CEF has also been involved in NPQ mechanisms as well as xanthophyll cycles depending upon the proton gradient (Zhang et al. 2014). These results suggest the photoprotective role of ET in FAinduced physiological changes. However, it was found that the ACC-induced NPQ and $\mathrm{Y}_{(\mathrm{CEF})} / \mathrm{Y}_{\text {(II) }}$ failed to protect the photosynthetic apparatus efficiently and facilitated the increasing formation of ROS (Borbély et al. 2019). Considering these observations and other results (Chen and Gallie 2015, Borbély et al. 2020), ET is suggested as a participant of CEF and NPQ, and therefore it plays a pivotal role in the regulation of photoprotection under the mycotoxin exposure.

Besides the effects of FA on the photosynthetic apparatus, the effects of FA on stomatal conductance and $\mathrm{CO}_{2}$ assimilation were also investigated. Our results exhibited a significant reduction in the stomatal conductance and $\mathrm{CO}_{2}$ assimilation in both $0.1 \mathrm{mM}$ and $1 \mathrm{mM}$ FA-treated plants as compared to controls after 24 and $72 \mathrm{~h}$, respectively. These findings coincide with the earlier studies with the strong stomatal closure and reduction in photosynthetic activity due to FA exposure (McElrone et al. 2003, Wu et al. 2008, Poór and Tari 2012, Singh et al. 2017). However, changes in the size of stomatal aperture are in a close relation with the water-use efficiency and water uptake (Romero-Aranda et al. 2001). Therefore, FA exposure caused stomatal closure after $24 \mathrm{~h}$ in both tomato genotypes influencing water uptake by plants. Although, $N r$ mutants showed basically a higher stomatal conductance and assimilation and thus a higher biomass production (Nascimento et al. 2020), FA exposure rapidly reduced these parameters. The stomatal closure restricted $\mathrm{CO}_{2}$ uptake in FA-treated plants and led to the suppression of photosynthetic activity (Sapko et al. 2011, Chen et al. 2015). In addition, it was also reported that ET induced stomatal closure in several plant species (Desikan et al. 
2006, Ceusters and Van de Poel 2018). Thus, the ETinduced decrease in stomatal conductance contributed to the ET-induced inhibition of the net $\mathrm{CO}_{2}$ assimilation rate, which limited $\mathrm{CO}_{2}$ diffusion to leaf mesophyll. It has also been reported that FA resulted in a decreased Chl content in the seedlings of watermelon (Wu et al. 2008), which contributed to the decreased photosynthetic activity. Furthermore, FA induced leaf wilting and necrosis (Wilhelmová et al. 2005, Singh et al. 2017). Similar tendencies were found in case of our results, $1 \mathrm{mM}$ FA induced loss of $\mathrm{Chl}(a+b)$ and elevated EL from the leaves of tomato after $72 \mathrm{~h}$. However, the decrease in Chl $(a+b)$ was more pronounced in $\mathrm{Nr}$ leaves suggesting the role of ET in this process.

The degree of necrosis is dependent on the ROSinduced lipid peroxidation (Czarnocka and Karpiński 2018). Interestingly, the MDA content was significantly higher in $\mathrm{Nr}$ plants as compared to WT after 24 and $72 \mathrm{~h}$ under $1 \mathrm{mM}$ FA treatments. These results showed that the lack of active ET signaling resulted in higher oxidative stress after FA exposure. Others found similar results in the case of abiotic stressors, where ET-receptor Arabidopsis mutants (etr1-3) deficient in ET signaling were more sensitive to excessive salt stress (Wang et al. 2009). At the same time, the electrolyte leakage increased in both WT and $N r$ leaves after the 72-h-long FA exposure as it was measured in the case of other Fusarium toxin such as FB1 (Asai et al. 2000, Plett et al. 2009). Thus, the ET-regulated defense reaction (e.g., NPQ, CEF) could only delay but not inhibit the cell death progression under FA exposure.

In conclusion, several mycotoxins are responsible for the induction of cell death in plants but their effects on photosynthesis are less studied. FA is one of the potential toxins produced by pathogenic Fusarium species. In the current study, the ET-dependent effects of FA were investigated in leaves of intact tomato plants. FA induced a significant ET emission from leaves in a concentrationand time-dependent manner suggesting ET's role in the regulation of defense- and/or cell death mechanisms. Based on the measurement of photosynthetic activity, FA significantly reduced $\mathrm{F}_{\mathrm{v}} / \mathrm{F}_{\mathrm{m}}$ as well as $\mathrm{Y}_{\text {(I) }}$ and $\mathrm{Y}_{\text {(II) }}$ which were accompanied with less efficient photoprotection in WT leaves. Although the treatment of tomato plants with both concentrations of FA decreased the effective quantum yield in both photosystems after $72 \mathrm{~h}$, the photoprotective processes, such as NPQ in parallel with CEF were activated more effectively in the leaves of $N r$. At the same time, the lipid peroxidation and the loss of $\mathrm{Chl}(a+b)$ were higher upon FA treatments in this tomato genotype. Conclusively, $\mathrm{Nr}$ tomato plants were more sensitive to FA phytotoxicity as compared to WT leaves, where inhibition of photosynthetic activity is an important step, suggesting the key role of ET in the activation of defense responses under the mycotoxin exposure.

\section{References}

Asai T., Stone J.M., Heard J.E. et al.: Fumonisin B1-induced cell death in Arabidopsis protoplasts requires jasmonate-, ethylene-, and salicylate-dependent signaling pathways. Plant Cell. 12: 1823-1835, 2000.
Bani M., Rispail N., Evidente A. et al.: Identification of the main toxins isolated from Fusarium oxysporum f. sp. pisi race 2 and their relation with isolates' pathogenicity. - J. Agr. Food Chem. 62: 2574-2580, 2014.

Borbély P., Bajkán S., Poór P., Tari I.: Exogenous 1-aminocyclopropane-1-carboxylic acid controls photosynthetic activity, accumulation of reactive oxygen or nitrogen species and macroelement content in tomato in long-term experiments. - J. Plant Growth Regul. 38: 1110-1126, 2019.

Borbély P., Poór P., Tari I.: Changes in physiological and photosynthetic parameters in tomato of different ethylene status under salt stress: Effects of exogenous 1-aminocyclopropane1-carboxylic acid treatment and the inhibition of ethylene signalling. - Plant Physiol. Bioch. 156: 345-356, 2020.

Bouizgarne B., El-Maarouf-Bouteau H., Frankart C. et al.: Early physiological responses of Arabidopsis thaliana cells to fusaric acid: toxic and signalling effects. - New Phytol. 169: 209-218, 2006.

Brown D.W., Butchko R.A.E., Busman M., Proctor R.H.: Identification of gene clusters associated with fusaric acid, fusarin, and perithecial pigment production in Fusarium verticillioides. - Fungal Genet. Biol. 49: 521-532, 2012.

Ceusters J., Van de Poel B.: Ethylene exerts species-specific and age-dependent control of photosynthesis. - Plant Physiol. 176: 2601-2612, 2018

Chang C.: Q\&A: How do plants respond to ethylene and what is its importance? - BMC Biol. 14: 7, 2016.

Chen L., Jia H., Tian Q. et al.: Protecting effect of phosphorylation on oxidative damage of D1 protein by down-regulating the production of superoxide anion in photosystem II membranes under high light. - Photosynth. Res. 112: 141-148, 2012.

Chen S., Kang Y., Zhang M. et al.: Differential sensitivity to the potential bioherbicide tenuazonic acid probed by the JIP-test based on fast chlorophyll fluorescence kinetics. - Environ. Exp. Bot. 112: 1-15, 2015.

Chen S., Strasser R.J., Qiang S.: In vivo assessment of effect of phytotoxin tenuazonic acid on PSII reaction centers. - Plant Physiol. Bioch. 84: 10-21, 2014.

Chen S., Yin C., Qiang S. et al.: Chloroplastic oxidative burst induced by tenuazonic acid, a natural photosynthesis inhibitor, triggers cell necrosis in Eupatorium adenophorum Spreng. BBA-Bioenergetics 1797: 391-405, 2010.

Chen Z., Gallie D.R.: Ethylene regulates energy-dependent nonphotochemical quenching in Arabidopsis through repression of the xanthophyll cycle. - PLoS ONE 10: e0144209, 2015.

Choudhury N.K., Behera R.K.: Photoinhibition of photosynthesis: role of carotenoids in photoprotection of chloroplast constituents. - Photosynthetica 39: 481-488, 2001.

Coll N.S., Epple P., Dangl J.L.: Programmed cell death in the plant immune system. - Cell Death Differ. 18: 1247-1256, 2011.

Czarnocka W., Karpiński S.: Friend or foe? Reactive oxygen species production, scavenging and signaling in plant response to environmental stresses. - Free Radical Bio. Med. 122: 4-20, 2018.

Czékus Z., Farkas M., Bakacsy L. et al.: Time-dependent effects of bentazon application on the key antioxidant enzymes of soybean and common ragweed. - Sustainability-Basel 12: 3872,2020

Desikan R., Last K., Harrett-Williams R. et al.: Ethylene-induced stomatal closure in Arabidopsis occurs via AtrbohF-mediated hydrogen peroxide synthesis. - Plant J. 47: 907-916, 2006.

Dong X., Ling N., Wang M. et al.: Fusaric acid is a crucial factor in the disturbance of leaf water imbalance in Fusariuminfected banana plants. - Plant Physiol. Bioch. 60: 171-179, 2012. 
Eagles E.J., Benstead R., MacDonald S. et al.: Impacts of the mycotoxin zearalenone on growth and photosynthetic responses in laboratory populations of freshwater macrophytes (Lemna minor) and microalgae (Pseudokirchneriella subcapitata). - Ecotox. Environ. Safe. 169: 225-231, 2019.

Edelman M., Mattoo A.K.: D1-protein dynamics in photosystem II: the lingering enigma. - Photosynth. Res. 98: 609-620, 2008.

Ederli L., Pasqualini S., Batini P., Antonielli M.: Photoinhibition and oxidative stress: effects on xanthophyll cycle, scavenger enzymes and abscisic acid content in tobacco plants. - J. Plant Physiol. 151: 422-428, 1997.

Fagundes-Nacarath I.R.F., Debona D., Rodrigues F.A.: Oxalic acid-mediated biochemical and physiological changes in the common bean-Sclerotinia sclerotiorum interaction. - Plant Physiol. Bioch. 129: 109-121, 2018.

Farooq M.A., Niazi A.K., Akhtar J. et al.: Acquiring control: The evolution of ROS-induced oxidative stress and redox signaling pathways in plant stress responses. - Plant Physiol. Bioch. 141: 353-369, 2019.

Gill S.S., Tuteja N.: Reactive oxygen species and antioxidant machinery in abiotic stress tolerance in crop plants. - Plant Physiol. Bioch. 48: 909-930, 2010.

Glazebrook J.: Contrasting mechanisms of defense against biotrophic and necrotrophic pathogens. - Annu. Rev. Phytopathol. 43: 205-227, 2005.

Guo Y., Lu Y., Goltsev V. et al.: Comparative effect of tenuazonic acid, diuron, bentazone, dibromothymoquinone and methyl viologen on the kinetics of Chl $a$ fluorescence rise OJIP and the $\mathrm{MR}_{820}$ signal. - Plant Physiol. Bioch. 156: 39-48, 2020.

He J., Yue X., Wang R., Zhang Y.: Ethylene mediates UV-Binduced stomatal closure via peroxidase-dependent hydrogen peroxide synthesis in Vicia faba L. - J. Exp. Bot. 62: 26572666, 2011.

Huang W., Zhang S.B., Cao K.F.: Cyclic electron flow plays an important role in photoprotection of tropical trees illuminated at temporal chilling temperature. - Plant Cell Physiol. 52: 297-305, 2011.

Ivanov B.N., Borisova-Mubarakshina M.M., Kozuleva M.A.: Formation mechanisms of superoxide radical and hydrogen peroxide in chloroplasts, and factors determining the signalling by hydrogen peroxide. - Funct. Plant Biol. 45: 102$110,2018$.

Jahns P., Holzwarth A.R.: The role of the xanthophyll cycle and of lutein in photoprotection of photosystem II. BBA-Bioenergetics 1817: 182-193, 2012.

Jiang C., Belfield E.J., Cao Y. et al.: An Arabidopsis soil-salinitytolerance mutation confers ethylene-mediated enhancement of sodium/potassium homeostasis. - Plant Cell 25: 35353552, 2013.

Jiao J., Sun L., Zhou B. et al.: Hydrogen peroxide production and mitochondrial dysfunction contribute to the fusaric acidinduced programmed cell death in tobacco cells. - J. Plant Physiol. 171: 1197-1203, 2014.

Jiao Y., Sun L., Song Y. et al.: AtrbohD and AtrbohF positively regulate abscisic acid-inhibited primary root growth by affecting $\mathrm{Ca}^{2+}$ signalling and auxin response of roots in Arabidopsis. - J. Exp. Bot. 64: 4183-4192, 2013.

Kalaji H.M., Goltsev V., Bosa K. et al.: Experimental in vivo measurements of light emission in plants: a perspective dedicated to David Walker. - Photosynth. Res. 114: 69-96, 2012.

Kamiyoshihara Y., Tieman D.M., Huber D.J., Klee H.J.: Ligandinduced alterations in the phosphorylation state of ethylene receptors in tomato fruit. - Plant Physiol. 160: 488-497, 2012.

Khan T.A., Yusuf M., Fariduddin Q.: Hydrogen peroxide in regulation of plant metabolism: Signalling and its effect under abiotic stress. - Photosynthetica 56: 1237-1248, 2018.

Klee H., Tieman D.: The tomato ethylene receptor gene family: form and function. - Physiol. Plantarum 115: 336-341, 2002.

Klughammer C., Schreiber U.: An improved method, using saturating light pulses, for the determination of photosystem I quantum yield via $\mathrm{P} 700^{+}$-absorbance changes at $830 \mathrm{~nm}$. Planta 192: 261-268, 1994.

Klughammer C., Schreiber U.: Saturation pulse method for assessment of energy conversion in PS I. - PAM Appl. Notes 1: 11-14, 2008.

Kurepin L.V., Ivanov A.G., Zaman M. et al.: Stress-related hormones and glycinebetaine interplay in protection of photosynthesis under abiotic stress conditions. - Photosynth. Res. 126: 221-235, 2015.

Kuźniak E.: Effect of fusaric acid on reactive oxygen species and antioxidants in tomato cell culture. - J. Phytopathol. 149: 575582,2001

Lanahan M.B., Yen H.C., Giovannoni J.J., Klee H.J.: The never ripe mutation blocks ethylene perception in tomato. - Plant Cell 6: 521-530, 1994.

Lei Y.B., Zheng Y.L., Dai K.J. et al.: Different responses of photosystem I and photosystem II in three tropical oilseed crops exposed to chilling stress and subsequent recovery. Trees-Struct. Funct. 28: 923-933, 2014.

Lievens B., Rep M., Thomma B.P.H.J.: Recent developments in the molecular discrimination of formae speciales of Fusarium oxysporum. - Pest Manag. Sci. 64: 781-788, 2008.

Liu M., Pirrello J., Chervin C. et al.: Ethylene control of fruit ripening: revisiting the complex network of transcriptional regulation. - Plant Physiol. 169: 2380-2390, 2015.

Liu Y.F., Qi M.F., Li T.L.: Photosynthesis, photoinhibition, and antioxidant system in tomato leaves stressed by low night temperature and their subsequent recovery. - Plant Sci. 196: 8-17, 2012.

Marzano M., Gallo A., Altomare C.: Improvement of biocontrol efficacy of Trichoderma harzianum vs. Fusarium oxysporum f. sp. lycopersici through UV-induced tolerance to fusaric acid. - Biol. Control 67: 397-408, 2013.

McElrone A.J., Sherald J.L., Forseth I.N.: Interactive effects of water stress and xylem-limited bacterial infection on the water relations of a host vine. - J. Exp. Biol. 54: 419-430, 2003.

Mersmann S., Bourdais G., Rietz S., Robatzek S.: Ethylene signaling regulates accumulation of the FLS2 receptor and is required for the oxidative burst contributing to plant immunity. - Plant Physiol. 154: 391-400, 2010.

Miyake C.: Alternative electron flows (water-water cycle and cyclic electron flow around PSI) in photosynthesis: molecular mechanisms and physiological functions. - Plant Cell Physiol. 51: 1951-1963, 2010

Munekage Y., Hojo M., Meurer J. et al.: PGR5 is involved in cyclic electron flow around photosystem I and is essential for photoprotection in Arabidopsis. - Cell 110: 361-371, 2002.

Nascimento V.L., Pereira A.M., Pereira A.S. et al.: Physiological and metabolic bases of increased growth in the tomato ethylene-insensitive mutant Never ripe: extending ethylene signaling functions. - Plant Cell Rep., 2020.

Noctor G., Reichheld J.P., Foyer C.H.: ROS-related redox regulation and signaling in plants. - Semin. Cell Dev. Biol. 80: 3-12, 2018.

Overmyer K., Brosché M., Kangasjärvi J.: Reactive oxygen species and hormonal control of cell death. - Trends Plant Sci. 8: 335-342, 2003.

Pare P.W., Farag M.A., Krishnamachari V. et al:: Elicitors and priming agents initiate plant defense responses. - Photosynth. Res. 85: 149-159, 2005. 
Partelli F.L., Batista-Santos P., Scotti-Campos P. et al.: Characterization of the main lipid components of chloroplast membranes and cold induced changes in Coffea spp. Environ. Exp. Bot. 74: 194-204, 2011.

Plett J.M., Cvetkovska M., Makenson P. et al.: Arabidopsis ethylene receptors have different roles in Fumonisin B1induced cell death. - Physiol. Mol. Plant Pathol. 74: 18-26, 2009.

Poór P., Borbély P., Bódi N. et al.: Effects of salicylic acid on photosynthetic activity and chloroplast morphology under light and prolonged darkness. - Photosynthetica 57: 367-376, 2019.

Poór P., Gémes K., Horváth F. et al.: Salicylic acid treatment via the rooting medium interferes with stomatal response, $\mathrm{CO}_{2}$ fixation rate and carbohydrate metabolism in tomato, and decreases harmful effects of subsequent salt stress. - Plant Biol. 13: 105-114, 2011.

Poór P., Kovács J., Borbély P. et al.: Salt stress-induced production of reactive oxygen and nitrogen species and cell death in the ethylene receptor mutant Never ripe and wild type tomato roots. - Plant Physiol. Bioch. 97: 313-322, 2015.

Poór P., Kovács J., Szopkó D., Tari I.: Ethylene signaling in salt stress- and salicylic acid-induced programmed cell death in tomato suspension cells. - Protoplasma 250: 273-284, 2013.

Poór P., Tari I.: Regulation of stomatal movement and photosynthetic activity in guard cells of tomato abaxial epidermal peels by salicylic acid. - Funct. Plant Biol. 39: 1028-1037, 2012.

Pospíšil P.: Molecular mechanisms of production and scavenging of reactive oxygen species by photosystem II. BBA-Bioenergetics 1817: 218-231, 2012.

Qin X., Zhang R.X., Ge S. et al.: Sphingosine kinase AtSPHK1 functions in fumonisin B1-triggered cell death in Arabidopsis. - Plant Physiol. Bioch. 119: 70-80, 2017.

Radić S., Domijan A.-M., Ljubimir K.G. et al.: Toxicity of nanosilver and fumonisin B1 and their interactions on duckweed (Lemna minor L.). - Chemosphere 229: 86-93, 2019.

Rani T.D., Rajan S., Lavanya L. et al.: An overview of fusaric acid production. - Adv. Biotech 8: 18-22, 2009.

Repka V., Fiala R., Pavlovkin J.: Role of ethylene and phospholipid-mediated signalling in mycotoxin-induced programmed cell death in the apical part of maize roots. Biologia 72: 378-387, 2017.

Romero-Aranda R., Soria T., Cuartero J.: Tomato plant-water uptake and plant-water relationships under saline growth conditions. - Plant Sci. 160: 265-272, 2001

Sapko O.A., Utarbaeva A.S., Makulbek S. et al.: Effect of fusaric acid on prooxidant and antioxidant properties of the potato cell suspension culture. - Russ. J. Plant Physl+ 58: 828-835, 2011.

Shakeel S.N., Wang X., Binder B.M., Schaller G.E.: Mechanisms of signal transduction by ethylene: overlapping and nonoverlapping signalling roles in a receptor family. - AoB Plants 5: plt010, 2013.

Shikanai T.: Cyclic electron transport around photosystem I: Genetic approaches. - Annu. Rev. Plant Biol. 58: 199-217, 2007.

Shikanai T.: Central role of cyclic electron transport around photosystem I in the regulation of photosynthesis. - Curr. Opin. Biotech. 26: 25-30, 2014.

Sims D.A., Gamon J.A.: Relationships between leaf pigment content and spectral reflectance across a wide range of species, leaf structures and developmental stages. - Remote Sens. Environ. 81: 337-354, 2002.

Singh V.K., Singh H.B., Upadhyay R.S.: Role of fusaric acid in the development of 'Fusarium wilt' symptoms in tomato: Physiological, biochemical and proteomic perspectives. Plant Physiol. Bioch. 118: 320-332, 2017.

Singh V.K., Upadhyay R.S.: Fusaric acid induced cell death and changes in oxidative metabolism of Solanum lycopersicum L. - Bot. Stud. 55: 66, 2014.

Srinivas C., Devi D.N., Murthy K.N. et al.: Fusarium oxysporum f. sp. lycopersici causal agent of vascular wilt disease of tomato: Biology to diversity - A review. - Saudi J. Biol. Sci. 26: 1315-1324, 2019.

Stępień Ł., Koczyk G., Waśkiewicz A.: Diversity of Fusarium species and mycotoxins contaminating pineapple. - J. Appl. Genet. 54: 367-380, 2013.

Sunil B., Talla S.K., Aswani V., Raghavendra A.S.: Optimization of photosynthesis by multiple metabolic pathways involving interorganelle interactions: resource sharing and ROS maintenance as the bases. - Photosynth. Res. 117: 61-71, 2013.

Sutherland M.L., Pegg G.F.: The basis of host recognition in Fusarium oxysporum f. sp. lycopersici. - Physiol. Mol. Plant Pathol. 40: 423-436, 1992.

Takahashi S., Milward S.E., Fan D.-Y. et al.: How does cyclic electron flow alleviate photoinhibition in Arabidopsis? Plant Physiol. 149: 1560-1567, 2009.

Trobacher C.P.: Ethylene and programmed cell death in plants. Botany 87: 757-769, 2009.

Wang H., Liang X., Wan Q. et al.: Ethylene and nitric oxide are involved in maintaining ion homeostasis in Arabidopsis callus under salt stress. - Planta 230: 293-307, 2009.

Wang M., Xiong Y., Ling N. et al.: Detection of the dynamic response of cucumber leaves to fusaric acid using thermal imaging. - Plant Physiol. Bioch. 66: 68-76, 2013b.

Wang P.C., Du Y.Y., Zhao X.L. et al.: The MPK6-ERF6-ROSresponsive cis-acting element $7 / \mathrm{GCC}$ box complex modulates oxidative gene transcription and the oxidative response in Arabidopsis. - Plant Physiol. 161: 1392-1408, 2013a.

Wang R., Huang J., Liang A. et al.: Zinc and copper enhance cucumber tolerance to fusaric acid by mediating its distribution and toxicity and modifying the antioxidant system. - Int. J. Mol. Sci. 21: 3370, 2020.

Wilhelmová N., Procházková D., Šindelářová M., Šindelář L.: Photosynthesis in leaves of Nicotiana tobaccum L. infected with tobacco mosaic virus. - Photosynthetica 43: 597-602, 2005.

Wu H.S., Bao W., Liu D.Y. et al.: Effect of fusaric acid on biomass and photosynthesis of watermelon seedlings leaves. Caryologia 61: 258-268, 2008.

Wu J.X., Wu J.L., Yin J. et al.: Ethylene modulates sphingolipid synthesis in Arabidopsis. - Front. Plant Sci. 6: 1122, 2015.

Wu N., Mao H.T., Chen M.Y. et al.: Different responses of photosystem and antioxidant defense system to three environmental stresses in wheat seedlings. - Photosynthetica 58: $87-99,2020$.

Xia X.J., Zhou Y.H., Shi K. et al.: Interplay between reactive oxygen species and hormones in the control of plant development and stress tolerance. - J. Exp. Bot. 66: 28392856, 2015.

Xiang M., Chen S., Wang L. et al.: Effect of vulculic acid produced by Nimbya alternantherae on the photosynthetic apparatus of Alternanthera philoxeroides. - Plant Physiol. Bioch. 65: 81-88, 2013.

Xing F., Li Z., Sun A., Xing D.: Reactive oxygen species promote chloroplast dysfunction and salicylic acid accumulation in fumonisin B1-induced cell death. - FEBS Lett. 587: 2164$2172,2013$.

Yen H.C., Lee S., Tanksley S.D. et al.: The tomato Never-ripe 
locus regulates ethylene-inducible gene expression and is linked to a homolog of the Arabidopsis ETR1 gene. - Plant Physiol. 107: 1343-1353, 1995.

Zavafer A., González-Solís A., Palacios-Bahena S. et al.: Organized disassembly of photosynthesis during programmed cell death mediated by long chain bases. - Sci. Rep.-UK 10: 10360, 2020.

Zhang G., Liu Y., Ni Y. et al.: Exogenous calcium alleviates low night temperature stress on the photosynthetic apparatus of tomato leaves. - PLoS ONE 9: e97322, 2014.

(C) The authors. This is an open access article distributed under the terms of the Creative Commons BY-NC-ND Licence. 